\title{
VIOLENCIA SIMBÓLICA: REVISIÓN DE LOS ESTUDIOS QUE ACUÑAN EL CONCEPTO EN AMÉRICA LATINA (2009-2019)
}

Luis Felipe Dávila, Carolina Moreno Quirós Cristian Arias Acevedo, Jorge David Vallejo Lorena Fajardo Puerta, Luis Alejandro Rivera Paula Durán Suárez

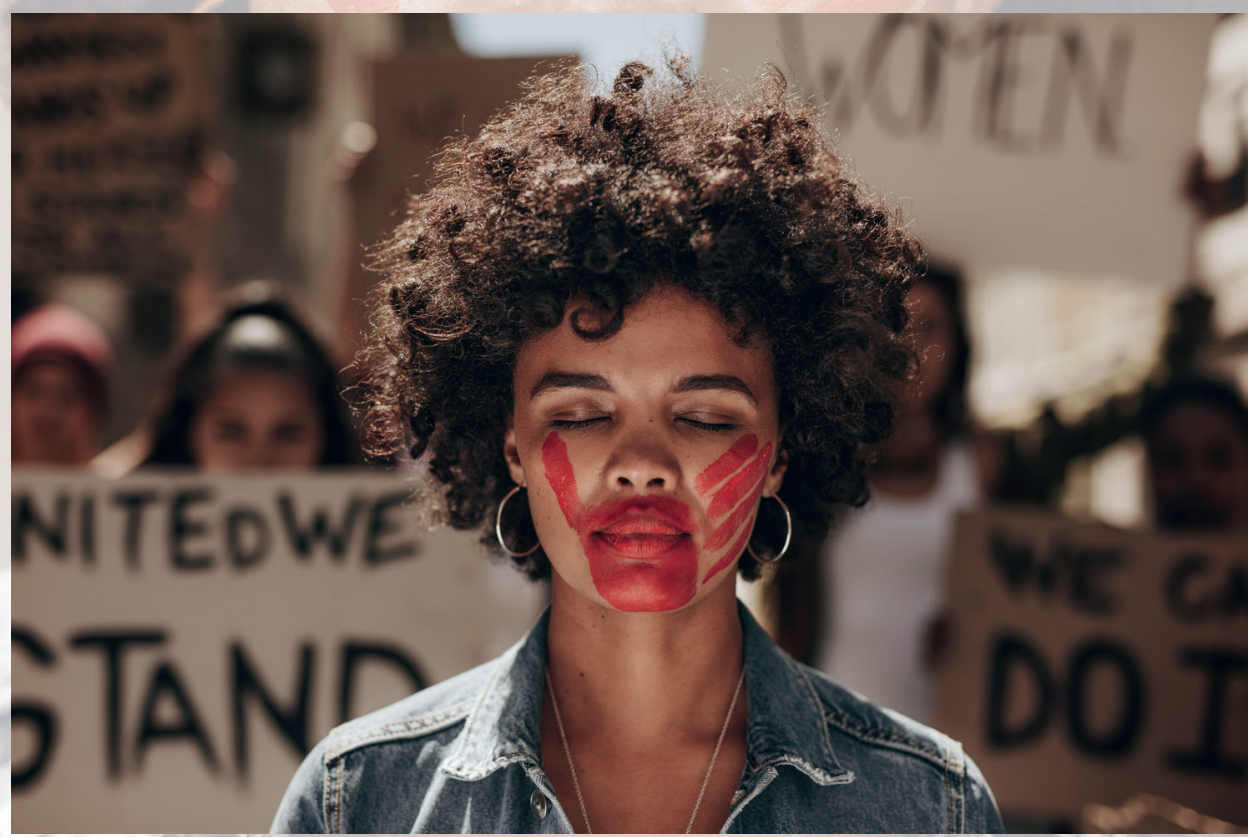





\title{
VIOLENCIA SIMBÓLICA: REVISIÓN DE LOS ESTUDIOS QUE ACUÑAN EL CONCEPTO EN AMÉRICA LATINA (2009-2019)*
}

\author{
Luis Felipe Dávila, Carolina Moreno Quirós \\ Cristian Arias Acevedo, Jorge David Vallejo \\ Lorena Fajardo Puerta, Luis Alejandro Rivera \\ Paula Durán Suárez \\ Universidad Católica de Colombia \\ UniVERSidad Autónoma LatinOAMERICANa
}

\section{Resumen}

El presente artículo es un estado del arte sobre el concepto de violencia simbólica en el contexto académico latinoamericano. El texto abarca la revisión de artículos, libros y tesis que abordan dicho concepto en el período 2009-2019. Si bien el concepto es introducido por el sociólogo francés Pierre Bourdieu, a finales del siglo pasado (XX), en el siguiente trabajo no se hará una revisión exhaustiva de la obra de Bourdieu, sino de los autores que han usado el concepto como eje de sus investigaciones sobre América Latina. El método utilizado consistió en una revisión documental con el software de análisis cualitativo ATLAS.ti y luego se hizo un examen más cualitativo y en profundidad de los textos. Se halló que el concepto se ha desarrollado en los siguientes campos académicos: estudios de género y feminismo; estudios sociales y políticos, y en análisis educativos y pedagógicos. La mayor utilización del concepto se ubica en el campo de los estudios de género, donde hay una mayor cantidad de publicaciones sobre esta categoría. La cantidad de estudios y la manera en la cual el concepto se ha instrumentalizado en los últimos diez años, da cuenta de que la obra de Bourdieu sigue siendo un objeto propicio para hacer de la sociología un deporte de combate.

\footnotetext{
El artículo, original e inédito, forma parte de los resultados de la investigación "Las violencias cotidianas: fundamentación de la línea de investigación y caracterización de las experiencias cotidianas de violencia e inseguridad en Medellín", financiado por la Universidad Autónoma Latinoamericana y el Observatorio de Seguridad Humana de Medellín (OSHM), adscrito a la Facultad de Derecho y Ciencias Políticas de la Universidad de Antioquia. Proyecto desarrollado entre enero y diciembre de 2019.
} 
Palabras clave: violencia simbólica, habitus, campos, género, Bourdieu.

Los autores: Luis Felipe Dávila, doctor en Humanidades, abogado y criminólogo. Docente de la Universidad Católica de Colombia. Correo electrónico: Ifdavila@ucatolica.edu.co

Carolina Moreno, maestranda en Educación y Derechos Humanos. Correo electrónico: carolina. morenoq@gmail.com

Cristian Arias Acevedo, maestrando en Educación y Derechos Humanos. Correo electrónico: cristian. arias5284@unaula.edu.co

Jorge David Vallejo, maestrando en Educación y Derechos Humanos. Correo electrónico: jorgedavidvallejo123@gmail.com

Lorena Fajardo Puerta, maestranda en Educación y Derechos Humanos. Correo electrónico: lfajardop1987@gmail.com

Luis Alejandro Rivera, maestrando en Educación y Derechos Humanos. Correo electrónico: luis. rivera2735@unaula.edu.co

Paula Durán Suárez, maestranda en Educación y Derechos Humanos. Correo electrónico: paula.1375@ hotmail.com

Recibido: 4 de marzo de 2020; evaluado: 25 de marzo de 2020; aceptado: 6 de abril de 2020. 


\title{
SYMBOLIC VIOLENCE: A REVIEW OF STUDIES THAT COINED THE CONCEPT IN LATIN AMERICA (2009-2019)
}

\author{
Luis Felipe Dávila, Carolina Moreno \\ Cristian Arias Acevedo, Jorge David Vallejo \\ Lorena Fajardo Puerta, Luis Alejandro Rivera \\ Paula Durán Suárez \\ Universidad Católica de Colombia \\ Universidad Autónoma Latinoamericana
}

\begin{abstract}
The purpose of this paper is to establish the current state of the art in the concept of symbolic violence in the Latin American academic context. To achieve this objective, the text includes a literature review of the articles, books, and theses that covered the concept between the years 2009 and 2019, as stated in the project's scope. Although French sociologist Pierre Bourdieu introduced the concept of symbolic violence at the end of the $20^{\text {th }}$ century, this paper is not an exhaustive review of Bourdieu's work, but rather of the authors who have used the concept as an explanatory axis in their research about Latin America. The researchers started with a paper review in the qualitative analysis software, ATLAS.ti, and then carried out a more thorough and qualitative analysis of the different papers. The concept of symbolic violence has been developed in the following academic fields: gender and feminism studies, social and political studies, and pedagogy and education. The field of gender studies extensively refers to symbolic violence, and is the field in which the highest number of publications on this topic are found. The magnitude of studies and the way in which the concept has been used in the last ten years demonstrates Bourdieu's work is still conducive to making sociology a combat sport.
\end{abstract}

Keywords: symbolic violence, fields, gender, Bourdieu.

The authors: Luis Felipe Dávila, doctor in humanities, attorney and criminologist. Professor at the Catholic University of Colombia. Email: Ifdavila@ucatolica.edu.co 
Carolina Moreno, master's student in Education and Human Rights. Email: carolina.morenoq@ gmail.com

Cristian Arias Acevedo, master's student in Education and Human Rights. Email: cristian.arias5284@ unaula.edu.co

Jorge David Vallejo, master's student in Education and Human Rights. Email: jorgedavidvallejo123@ gmail.com

Lorena Fajardo Puerta, master's student in Education and Human Rights. Email: 1fajardop1987@ gmail.com

Luis Alejandro Rivera, master's student in Education and Human Rights. Email: luis.rivera2735@ unaula.edu.co

Paula Durán Suárez, master's student in Education and Human Rights. Email: paula.1375@hotmail.com.

Received: March 4, 2020; evaluated: March 25, 2020; accepted: April 6, 2020. 


\title{
VIOLÊNCIA SIMBÓLICA: REVISÃO DOS ESTUDOS QUE CUNHAM O CONCEITO NA AMÉRICA LATINA (2009-2019)
}

\author{
Luis Felipe Dávila, Carolina Moreno \\ Cristian Arias Acevedo, Jorge David Vallejo \\ Lorena Fajardo Puerta, Luis Alejandro Rivera \\ Paula Durán Suárez \\ Universidad Católica de Colombia \\ Universidad Autónoma Latinoamericana
}

\section{Resumo}

Este artigo é um estado da arte sobre o conceito de violência simbólica no contexto acadêmico latino-americano. O texto abrange a revisão de artigos, livros e teses que abordam o conceito de 2009 a 2019. Embora o conceito tenha sido introduzido pelo sociólogo Pierre Bourdieu, no final do século XX, neste trabalho, não é feita uma revisão exaustiva da obra do referido autor, mas dos que têm usado o conceito como eixo de suas pesquisas sobre a América Latina. O método utilizado consistiu em uma revisão documental com o software de análise qualitativa ATLAS.ti e, em seguida, foi feita uma análise mais qualitativa e profunda dos textos. Verificou-se que o conceito foi desenvolvido nos seguintes campos acadêmicos: estudos de gênero e feminismo; estudos sociais e políticos, e em análises educativas e pedagógicas. A maior utilização do conceito está no campo dos estudos de gênero, em que há uma maior quantidade de publicações sobre a categoria. A quantidade de estudos e a maneira em que o conceito é instrumentalizado nos dez anos do estudo evidenciam que a obra de Bourdieu continua sendo um objeto propício para fazer da sociologia um campo de luta.

Palavras-chave: violência simbólica, habitus, campos, gênero, Bourdieu.

Os autores: Luis Felipe Dávila, doutor em Humanas, advogado e criminalista. Docente da Universidad Católica de Colombia. E-mail: lfdavila@ucatolica.edu.co 
Carolina Moreno, mestranda em Educação e Direitos Humanos. E-mail: carolina.morenoq@gmail.com Cristian Arias Acevedo, mestrando em Educação e Direitos Humanos. E-mail: cristian.arias5284@ unaula.edu.co

Jorge David Vallejo, mestrando em Educação e Direitos Humanos. E-mail: jorgedavidvallejo123@ gmail.com

Lorena Fajardo Puerta, mestranda em Educação e Direitos Humanos. E-mail: lfajardop1987@gmail.com Luis Alejandro Rivera, mestrando em Educação e Direitos Humanos. E-mail: luis.rivera2735@ unaula.edu.co

Paula Durán Suárez, mestranda em Educação e Direitos Humanos. E-mail: paula.1375@hotmail.com.

Recebido: 4 de março de 2020; avaliado: 25 de março de 2020; aceito: 6 de abril de 2020. 
"La inculcación de lo arbitrario deroga lo arbitrario de lo inculcado y de las significaciones inculcadas".

\section{Introducción}

Pierre Bourdieu es uno de los mayores sociólogos del siglo XX. Su propuesta sigue teniendo un gran influjo en las ciencias sociales y es considerado uno de los intelectuales más citados y más importes de los últimos tiempos. Su obra es extensa: abarca 37 libros y más de 400 artículos y sus conceptos básicos son usados en la mayoría de las ciencias sociales: sociología, antropología, educación, criminología, derecho, ciencia política. Gran parte del interés por Bourdieu se centra en el hecho de que, para él, lo principal no es inculcar una teoría pura, sino transmitir unas disposiciones para el quehacer científico.

Asimismo, pretende proponer un modelo bastante general para pensar nuestras sociedades altamente diferenciadas: un cosmos social está constituido por un conjunto de esos microcosmos sociales relativamente autónomos, espacios de relaciones objetivas que presentan sus propias lógicas y necesidades irreductibles. Dichos microespacios son los campos sociales que se diferencian radicalmente entre sí, por ejemplo, un campo religioso, uno económico, uno político y uno literario se rigen por lógicas diferentes.

Bourdieu construyó su concepto de campo al combinar propiedades pertenecientes a universos teóricos diferentes: elementos de Durkheim, otros de Weber y otros de Marx. Para Bourdieu, campos, habitus e instituciones se interrelacionan y permiten entender el universo social. Se podrían explicar de la siguiente manera: las instituciones son la historia objetivada en las cosas y, a su vez, el habitus es la historia encarnada en los cuerpos bajo un sistema de disposiciones duraderas y con un grado alto de estabilidad, pues, "si bien esas disposiciones pueden modificarse durante el transcurso de nuestras experiencias, están fuertemente arraigadas en nosotros y por ello tienden a resistir al cambio, marcando así cierta continuidad en la vida de una persona". ${ }^{2}$

Pierre Bourdieu, Bosquejo de una teoría de la práctica (Buenos Aires: Prometeo Libros, 2012), 202.

Philippe Corcuff, Las nuevas sociologías. Principales corrientes y debates, 1980-2010 (Buenos Aires, Siglo XXI editores, 2013), 43-44. 
Un campo es un microcosmos incluido en un macrocosmos constituido por un espacio social global; cada campo posee reglas de juego y desafíos específicos, los cuales no son comparables a las reglas de juego o a los desafíos de otro campo. De igual modo, es un sistema o un espacio estructurado de posiciones ocupadas por diferentes agentes de campo. Las prácticas o estrategias de los agentes son comprensibles si son relacionadas con sus posiciones en el campo. Dentro del campo existes tensiones y relaciones de dominación y sumisión, prácticas de conservación que pueden ser violentas y prácticas de subversión que también pueden serlo.

El campo es un espacio de disputas entre diferentes agentes por las posiciones de dominación. El objetivo de esas luchas es la apropiación del capital específico de ese campo (en la obra de Bourdieu existen múltiples capitales, no solo el económico) o la redefinición de ese capital, el cual está distribuido de manera desigual en el seno del campo. En ese sentido, hay posiciones de dominio y luchas por el capital. Tal distribución desigual determina la estructura del campo y lo define, por lo que, el estado de las relaciones de fuerza (agentes/instituciones) en las confrontaciones del campo determina roles, posiciones y tipos de capital. Dentro de cada campo se tejen relaciones de dominación y sumisión; de ahí que se pueda afirmar que los campos no son neutrales. Ni siquiera los campos académicos y artísticos escapan a estas dinámicas.

A cada campo le corresponde un habitus (sistema de disposiciones incorporadas) propio y solo quienes tienen incorporado ese habitus propio del campo están en condiciones de disputar el juego de acreditar su importancia. Todo campo posee una autonomía relativa: las luchas que se desarrollan en su interior tienen una lógica propia (económica, social, política) que, aunque pueden interactuar con dinámicas exteriores, tienden a no perder sus condiciones de autonomía.

Dentro de dichos campos se gestan relaciones violentas que pueden ser directas o simbólicas. En este texto tendrá especial atención el concepto de violencia simbólica, el cual busca explicar las formas de dominación blandas que consiguen ganar la adición de los dominados. Blandas, en relación con las formas brutales basadas en la fuerza física o armada (aunque la violencia física siempre es simbólica también). Y es violencia porque, pese a ser blanda, no deja de generar efectos adversos en los sujetos que la padecen, al provocar vergüenza de sí mismos, autodescrédito, autocensura o autoexclusión. 
Es simbólica por el hecho de exceder la esfera de las significaciones, más precisamente, el sentido que los dominados le confieren al mundo social y a su lugar en el mundo. Es una violencia disfrazada que no solo se ejerce por el lenguaje, sino también por los gestos y por las cosas (los trabajos como Las meditaciones pascalianas y La dominación masculina son textos de referencia al respecto).

La violencia simbólica se transforma en coerción en la medida en que el dominado se adhiere a las posiciones dominantes que inculcan clasificaciones que nos resultan neutrales (alto/bajo, masculino/femenino, blanco/negro, heterosexual/homosexual, rico/pobre, Estado/individuo), las cuales terminan siendo naturalizadas. De hecho, la dominación puede ser ejercida independientemente de la consciencia y la voluntad, ya que no es suficiente ser consciente de ella para librarse de su influjo. ${ }^{3}$

La obra de Pierre Bourdieu es tan caótica y sistemática a la vez, tan prolífica y vital, que podría pensarse que de ella devienen tres vertientes principales:

1. Los trabajos especializados en la educación y en las formas de reproducción de las desigualdades y de las violencias cotidianas. Esta línea se basa principalmente en su obra La reproducción y, en menor medida, en Los herederos, traducida al español como Los estudiantes y la cultura (ambas escritas en conjunto con Passeron).

2. Los trabajos más antropológicos, que abordan de manera más profunda los conceptos de habitus, capital y violencia simbólica. Se basan en los trabajos etnográficos de su juventud en Argelia, donde se introduce el uso de fotografías como método social de análisis, y aparece el trabajo acerca de las condiciones de vida del proletariado rural y acerca de la dominación masculina sobre las mujeres africanas. También se podría enlistar en esta vertiente el texto Una teoría de la práctica.

3. Se presentan los análisis de los sociólogos de la cultura, de la estética de las clases sociales, de la vida cotidiana y de la construcción de los gustos. Son trabajos en los que Bourdieu introduce la vida cotidiana en los análisis sociológicos. El texto clave para entender esos procesos es La distinción.

3 Afrânio Mendes Catani et al., Vocabulário Bourdieu (Belo Horizonte: Autêntica Editora, 2017), 360. 
No obstante, dichas categorías reaparecen en otros textos y entrevistas dispersas, por lo cual es necesario tratar muchos otros textos de su autoría para consolidar un proceso más orgánico y completo. A manera de cierre transitorio, para Bourdieu, las estructuras sociales llevan una doble vida, existen dos veces: la primera, como campo y la segunda, como habitus. En dichas existencias se reproducen los elementos culturales, los gustos y los procesos de dominación, y se reparte el capital. Empero, esto no es neutral ni pacífico: es un proceso mediado por la violencia real y simbólica, violencia que está naturalizada e inscrita en los cuerpos a manera de habitus. Habitus y violencia serán conceptos fundamentales en esta pesquisa.

Cabe aclarar que la importancia de la obra de Bourdieu no radica en un único concepto, teoría, prescripción metodológica u observación empírica. Para retomar un latinismo a menudo empleado (y a manera de reiteración), sería el modus operandi de la sociología de Bourdieu — y no su opus magnum — lo que mejor definiría su originalidad. ${ }^{4}$

A partir de lo anterior, el presente texto retoma la categoría de violencia simbólica, la cual se encuentra transversalizada en la obra del autor. Se identificó que esta categoría ha sido abordada y estudiada en diferentes campos de investigación y áreas de conocimiento; por ello, se adelantó la construcción de un estado del arte, que tuvo por finalidad comprender cómo ha sido abordada la categoría en cuestión, en qué campos se trabaja principalmente y desde cuáles enfoques. Es así como se adelantó la búsqueda de artículos de la última década en los cuales se observara este concepto desde Pierre Bourdieu, pero dado el interés central del presente trabajo, se prioriza para la lectura y el análisis los trabajos que se adelantaron en América Latina.

Tras esta breve contextualización de la obra de Bourdieu, a continuación se explica la metodología utilizada por el equipo de autores que participó en esta investigación. En segundo lugar, se presentan los hallazgos encontrados en las publicaciones seleccionadas para el análisis, con una mayor profundización en los campos de género y feminismo, social, político, educativo y pedagógico. Para finalizar, se aporta un acápite de discusiones y conclusiones, con algunos aprendizajes y reflexiones en el camino trazado.

4 Pierre Bourdieu y Loïc Wacquant, Una invitación a la sociología reflexiva (Buenos Aires: Siglo XXI editores, 2005), 14 . 


\section{Metodología}

El ejercicio fue desarrollado en un período de un año académico, entre enero y diciembre de 2019, mediante la exploración de bases de datos y su posterior sistematización con el software de investigación ATLAS.ti. El presente acápite ahonda en tres momentos particulares de la etapa metodológica: i) elaboración de instrumentos para construir en estado del arte; ii) recolección de la información, y iii) sistematización por medio de un programa especializado en análisis cualitativo de información.

\subsection{Construcción de instrumentos}

Durante el mes de agosto se construyeron los instrumentos necesarios para el ejercicio de organización y computarización de la indagación en cuestión. El primer instrumento, de corte principalmente cuantitativo, fue una matriz de estado del arte, para que el equipo de investigación pudiera ingresar la información de sus ejercicios de revisión en una hoja en formato de Excel u hoja de cálculo hospedada en el servicio de Google Drive. Se definieron diecisiete campos de información para optimizar su recolección: 1) título del texto; 2) autores; 3) acceso (limitado o abierto); 4) idioma de publicación; 5) país de publicación; 6) ciudad de publicación; 7) territorio de análisis; 8) macromolde; 9) metodología; 10) manifestación principal de violencia simbólica; 11) tipo de publicación; 12) número de páginas; 13) fuente; 14) recurso web; 15) enlace; 16) responsable de identificación de texto, y 17) abstract o resumen.

El segundo instrumento construido correspondió al modelo de fichaje de revisión bibliográfica, que se empleó para analizar la información a profundidad, en un ejercicio cualitativo. Para este instrumento, se establecieron los campos de: 1) hallazgos generales del texto; 2) observaciones, hallazgos o reflexiones en relación con Pierre Bourdieu en el texto; 3 ) vacíos del texto (en relación con los objetivos del programa de investigación); 4) citas relevantes; 5) categorías encontradas, y 6) bibliografía relevante citada. Una vez establecidos estos elementos, el equipo procedió con el siguiente momento metodológico: la recolección directa de la información para la elaboración del estado del arte. 


\subsection{Recolección de información}

Las categorías que definieron el levantamiento fueron "violencia simbólica" (idealmente, en atención a las definiciones exploradas por Pierre Bourdieu) o, en su defecto, estudios o escritos cuyos resúmenes tuvieran información relevante a los siete tópicos principales del programa de investigación al que atiende el presente ejercicio. Estos fueron establecidos como las manifestaciones de violencia simbólica en: 1) el barrio; 2) la escuela; 3) la vía pública; 4) en contra de los extranjeros; 5) el hogar; 6) el trabajo, y 7) la cárcel.

Sumado a lo anterior, los criterios espacio-temporales fueron establecidos en relación con publicaciones que se hubieran realizado en la última década (2009-2019) y que, a su vez, registraran sus experiencias en el contexto latinoamericano, priorizando los hallazgos sobre Medellín, Colombia y América Latina, desde un acercamiento general. A partir de las categorías establecidas, se dio inicio a la fase de recolección de información. Para esto, el equipo de investigación tuvo en cuenta un total de veintisiete fuentes, entre las cuales hubo bibliotecas, repositorios universitarios y bases de datos académicas, entre otras. Estas fuentes fueron:

Tabla 1. Fuentes de información consultada para elaboración de estado del arte

\begin{tabular}{|l|l|l|}
\hline Amelica & DOAJ & Redalyc \\
\hline AULA & E-Journal & Research Trends \\
\hline Biblioteca Jurídica Colombiana & ERIC & Scielo \\
\hline Biblioteca Nacional de Colombia & Eumed & Science Direct \\
\hline Biblioteca Virtual de Antioquia & $\begin{array}{l}\text { Fondo Editorial Universidad Cató- } \\
\text { lica de Oriente }\end{array}$ & Tabula Rasa \\
\hline $\begin{array}{l}\text { Biblioteca Virtual Luis Ángel Arango } \\
\text { (Banco de la República) }\end{array}$ & Latindex & Google Académico \\
\hline $\begin{array}{l}\text { Biblioteca Virtual Miguel de } \\
\text { Cervantes }\end{array}$ & Misión Jurídica & Revistas Científicas In Crescendo \\
\hline Clacso & Openlibra & NOVA \\
\hline Dialnet & Publicaciones Eafit & Taylor \& Francis Group \\
\hline
\end{tabular}

Fuente: elaboración propia

Durante esta fase, cada integrante del equipo de investigación asumió la responsabilidad de explorar un conjunto de bases de datos y registrar sus hallazgos en el instrumento de recolección inicial, es decir, en la matriz de Excel hospedada en el servicio de Google Drive. Sumado a lo anterior, durante el mes de octubre se 
realizó un primer abordaje conceptual de los textos recopilados; se priorizaron los elementos identificados en el ítem 10 de la matriz de estado del arte (Manifestación principal de violencia simbólica $)^{5}$ y se distribuyeron entre el equipo de investigación para su análisis a profundidad con el segundo instrumento elaborado: la ficha de revisión bibliográfica. Luego se procedió a la sistematización inicial de la información. Para responder a esta fase, se recurrió a un software especializado en análisis cualitativo para procesar la información recopilada en el instrumento de fichas de revisión bibliográfica.

\subsection{Sistematización inicial de la información}

Para este momento metodológico, el equipo de investigación utilizó el software de análisis cualitativo ATLAS.ti en su séptima versión, en función de su facilidad para organizar información y procesar las fichas, y se hizo la exploración de los textos de mayor relevancia. Para esto, el equipo elaboró una unidad hermenéutica (UH) en la cual recurrió a tres funciones principales para organizar las fichas: la función de documentos primarios (DP), códigos y familias. Para organizar los DP, se tomaron como referencia las fichas elaboradas. En cuanto a los códigos, se partió de las categorías, las subcategorías y los observables planteados para el estado del arte, los cuales a su vez fueron agrupados para definir las familias. Estas familias se establecieron para los DP en torno a tres criterios centrales: manifestaciones de violencia simbólica, macromoldes y tiempo de publicación. Por otro lado, para los códigos, las familias establecidas fueron: hallazgos, vacíos e información de soporte.

Dentro de la familia de hallazgos se establecieron los códigos: "Hallazgos generales", "Hallazgos relacionados con Bourdieu" y "Violencia simbólica". Dentro de la familia de vacíos se empleó un único código denominado "Vacíos". Por último, en la familia de información de soporte se codificaron las citas relevantes, la bibliografía relevante y las referencias bibliográficas de los textos en formato APA sexta edición. Una vez codificados todos los DP (correspondientes a veinte fichas bibliográficas en total), el equipo empleó la herramienta de Informes del ATLAS.ti, la cual, por medio de la recopilación de los códigos establecidos y la revisión de los documentos primarios o las fichas de revisión bibliográfica en torno a estos, permitió generar un informe de investigación respecto a cada código. Es decir, todos los hallazgos generales,

Fue en torno a este ítem que se identificaron los campos temáticos que permitieron al equipo de investigación desarrollar el acápite de hallazgos, en tanto estas manifestaciones de violencia fueron agrupadas y organizadas dentro de la unidad hermenéutica para detectar tendencias de publicación, número de publicación por cada línea temática, etc. 
hallazgos frente a la obra de Bourdieu, los vacíos y las categorías emergentes, y demás asuntos de relevancia para la investigación fueron organizados en informes específicos. Esto facilitó el abordaje de la información, al eliminar la necesidad de retomar constantemente las veinte fichas al mismo tiempo. Así pues, al tomar como referencia los elementos resultantes de los ejercicios ilustrados, se propone, en adelante, explorar algunos de los hallazgos, las reflexiones, las críticas y demás elementos que terminaron por configurar el ejercicio de estado del arte al que atiende la primera fase.

\section{Hallazgos generales}

A continuación se presentan algunos de los hallazgos generales, de corte descriptivo y cuantitativo, identificados a partir del análisis y del procesamiento de las publicaciones encontradas, para las cuales se tuvo en cuenta la función de nube de palabras del ATLAS.ti y la generación de tablas y gráficos dinámicos en Excel, con el fin de identificar tendencias y particularidades en asuntos como los años en los que fueron publicados el mayor número de textos, al igual que los macromoldes ${ }^{6}$ en los que estos se inscriben, para luego indagar sobre asuntos de fondo o estructurales de la producción bibliográfica sobre violencia simbólica en la última década.

Al retomar las funcionalidades de organización de familias del software ATLAS.ti, fue posible identificar que, de los 134 textos encontrados, un $60 \%$ está disponible en español; un 37 \% en inglés, y un 3 \% restante en alemán. A partir de la función de nube de palabras que provee el software y con referencia en los resúmenes de los textos en español, fue posible identificar que la palabra "violencia" fue la más utilizada, seguida por la palabra "simbólica", con cien menciones, y de las palabras "social" y "sociales" con 81 y 61 referencias respectivamente; prosigue "Bourdieu" en 57 interacciones y continúan otras palabras como "poder", "mujeres", "relaciones", y otras. Por su parte, los textos en inglés destacan en su nube de palabras términos como "violence", "women", "symbolic", liberation" y "school", entre otros.

6 El equipo entendió por macromoldes los grandes marcos de pensamiento que, según Losada y Casas, pueden servir de referente epistemológico para la realización de ejercicios de análisis político (sin limitarse a este campo). En esta medida, de manera muy general, es posible entender que el macromolde empírico-analítico propende por priorizar los asuntos empíricamente comprobables y establecer leyes de corte positivista o similares; por otro lado, el histórico-hermenéutico apunta a desarrollar ejercicios de comprensión e interpretación de características específicas de la realidad desde orillas primariamente cualitativas; el crítico procura cuestionar estructuras tradicionales de pensamiento; y el posmoderno ofrecer acercamientos metodológicos y analíticos desligados de las concepciones tradicionales de desarrollo científico devenidas de la modernidad. Rodrigo Losada y Andrés Casas, Enfoques para el análisis político: historia, epistemología y perspectivas de la ciencia política (Bogotá: Pontificia Universidad Javeriana, 2008). 
Se encontró que, en América Latina, en estos últimos diez años, la mayoría de estudios en español sobre violencia simbólica que se han publicado en revistas indexadas o en repositorios de universidades han sido en el campo del género y del feminismo (dieciocho publicaciones encontradas), seguidos del campo social (quince publicaciones), donde se estudian diversas poblaciones como habitantes de calle, personas que ejercen la prostitución, personas privadas de la libertad y migrantes, entre otros. En tercer lugar aparece el campo político (catorce publicaciones), ligado en la mayoría de estudios al conflicto armado y a la seguridad en las ciudades. En cuarto lugar se ubica el campo educativo o pedagógico (trece publicaciones).

Cabe aclarar que, por cuestiones de extensión en este artículo, no se profundizará en otros campos en los que también se encontraron publicaciones que abordaban la categoría de violencia simbólica; estos son, en orden de cantidad: cultural y artístico (cuatro publicaciones); económico (cuatro publicaciones); histórico (cuatro publicaciones); psicológico (tres publicaciones); deportivo (tres publicaciones); televisivo y medios de comunicación (dos publicaciones); familiar (dos publicaciones); lenguaje (dos publicaciones); jurídico (una publicación); carcelario-penitenciario (una publicación); filosófico (una publicación) y religioso (una publicación).

En cuanto a las técnicas y metodologías de investigación prevalecen los enfoques cualitativos, derivados, en su mayoría, de pesquisas realizadas desde el macromolde histórico-hermenéutico, como puede apreciarse en la Figura 1. Pese a lo anterior, no es imposible ni inconveniente establecer formas de análisis o aproximaciones a la violencia simbólica desde enfoques cuantitativos más cercanos a la corriente empírico-analítica, ${ }^{7}$ como bien procuran Cendales, quien propende por revisar, por medio de ecuaciones, los elementos que constituyen los intercambios simbólicos de los individuos según los planteamientos de Bourdieu.

Andrés Cendales, "Pensando con Bourdieu contra Bourdieu: una crítica metodológica del mercado lingüístico", Cuadernos de Economía 30, núm. 54 (2011): 193, https://revistas.unal.edu.co/index.php/ceconomia/ article/view/24137 (acceso noviembre 15, 2019). 


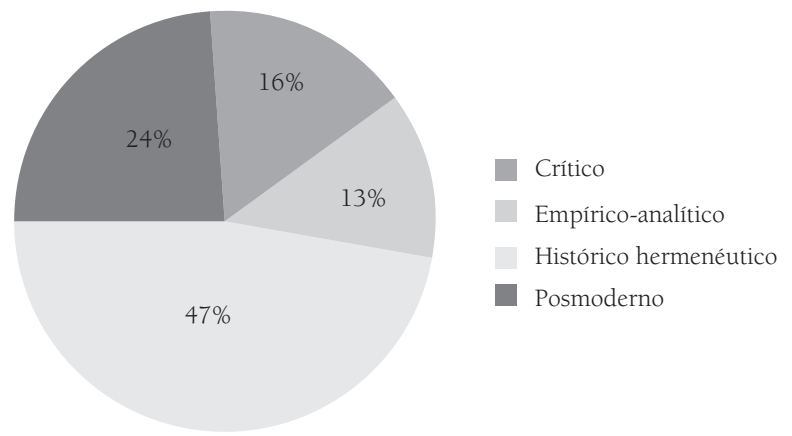

Figura 1. Análisis de los textos basados en macromoldes (2009-2019)

Fuente: elaboración propia

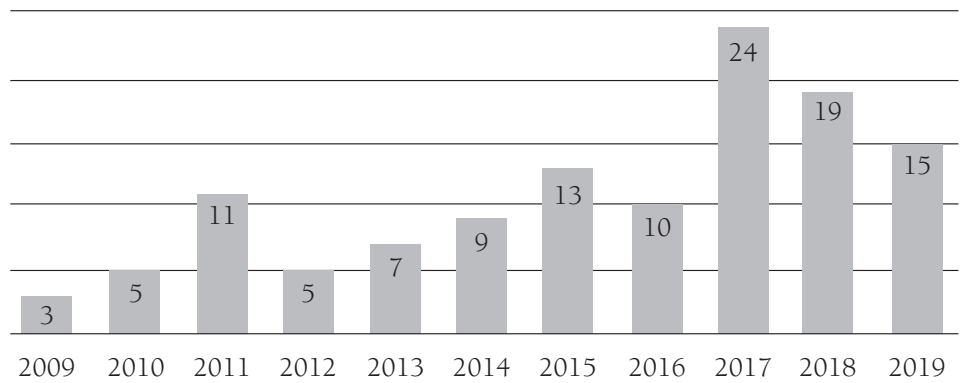

Figura 2. Años de mayor cantidad de publicaciones sobre la categoría de violencia simbólica

Fuente: elaboración propia

La conclusión es que el concepto sigue vigente y es apropiado por los académicos latinoamericanos; de hecho, en los últimos tres años se presenta el mayor número de apariciones (Figura 1), lo cual desvirtúa algunas hipótesis del equipo que consideraba que la obra de Bourdieu y sus conceptos fundamentales habían caído en desuso. Si bien el número de publicaciones presenta variaciones temporales, se puede afirmar que, en el período examinado, la tendencia es al alza hasta el año 2017, que fue también el año de mayor aparición de artículos relacionados con el concepto; más adelante se presenta un descenso escalonado de 24 en 2017 a 19 en 2018 y luego a 15 en 2019. Vale la pena agregar que las cifras de 2019 no están consolidadas en un cien por ciento, lo cual implica que puede aumentar. 


\section{Hallazgos específicos}

A partir de aquí se expondrán los principales resultados de la investigación, en los cuales se esbozan algunos hallazgos, reflexiones, cuestionamientos y vacíos, con base en los siguientes ejes o campos, ordenados según la cantidad de publicaciones identificadas: 1) violencia simbólica en el campo del género y feminismo; 2) violencia simbólica en el campo social; 3) violencia simbólica en el campo político, y 4) violencia simbólica en el campo educativo y pedagógico.

\subsection{Violencia simbólica en el campo de género y feminismo}

En este campo fue identificada la mayor cantidad de publicaciones. Se hallaron varios artículos que analizan las relaciones de dominación y violencia simbólica entre los géneros, las cuales se han construido en la sociedad de manera desigual y se reproducen en diferentes campos, debido a que este es un tipo de violencia simbólica estructural que se aloja no solo en el imaginario y en el constructo social, sino que además forma parte de la cotidianidad de un entorno social definido.

La dominación masculina sirve mejor que cualquier otro ejemplo para mostrar una de las características principales de la violencia simbólica: se ejerce al margen de los controles de la conciencia y de la voluntad, "en las tinieblas de los esquemas del habitus, que son a la vez sexuados y sexuantes", mediante una coerción paradójicamente consentida: una presión sutil sobre los cuerpos y las mentes, no percibida como tal, sino como el orden natural de las cosas. ${ }^{8}$

Puede darse por sentado y asumirse que las cosas siempre fueron así, ya que este tipo de violencia se reproduce de forma sistemática, se naturaliza y se incorpora en los agentes, lo que hace que la conciencia no se percate de dicha violencia; es por ello que, para Bourdieu, es crucial alejarse de las filosofías de la conciencia, pues estas inciden en que la dominación simbólica se perpetúe. ${ }^{9}$

$8 \quad$ Manuel Fernández, "La noción de violencia simbólica en la obra de Pierre Bourdieu: una aproximación crítica", Cuadernos de trabajo social 18, núm. 30 (junio 2005): 24, http:/www.enlinea.cij.gob.mx/Cursos/ Hospitalizacion/pdf/PierreBourdieu.pdf (acceso noviembre 15, 2019).

$9 \quad$ Pierre Bourdieu, "Symbolic Violence". Revista Latina de Sociología, núm. 2 (2012): 64-69, http://hdl.handle. net/2183/12136 (acceso noviembre 15, 2019). 
El artículo titulado "Misoginia y violencia hacia las mujeres: dimensiones simbólicas del género y del patriarcado"10 ejemplifica lo anterior desde el análisis crítico de los relatos míticos de Pandora y de Eva, los cuales emergen dos elementos cardinales que reproducen la violencia simbólica hacia las mujeres: la devaluación femenina y el imperativo de ser para otro. En ambos mitos se construye un discurso misógino que desvaloriza a las mujeres desde el instante de la creación, transmiten expresiones sexistas sobre los orígenes de la humanidad y naturalizan la violencia de género, que persiste desde los orígenes de la cultura occidental hasta la actualidad.

En otro sentido, los trabajos recientes de Alvarado Fajardo y Ortiz ${ }^{11}$ y el de Baird ${ }^{12}$ coinciden en una temática que había sido poco explorada y es la violencia simbólica hacia los hombres desde un enfoque de género que, en línea con la teoría del habitus y las disputas en los campos, de Pierre Bourdieu, plantea que la coerción simbólica que pesa sobre la identidad sexual que se ha construido de "hombre" lo lleva con más facilidad a vincularse a grupos criminales y a utilizar estrategias y métodos de violencia real para acceder a los diferentes capitales.

Se destacan los trabajos sobre género y violencia política en América Latina realizados por Krook y Restrepo, ${ }^{13}$ así como en contextos electorales, como es el caso del estudio comparativo que desarrollan Rodríguez, González y Messenet. ${ }^{14}$ En ambos estudios se analizó la violencia contra las mujeres en los escenarios de la vida política, tendiente a impedir la participación de ellas y perpetuar el predominio de los hombres en el sector de la administración pública y en cargos de elección popular. Por otro lado, se encontraron investigaciones sobre violencia simbólica y género en el campo de la escuela, como la de Pinzón, Armas, Aponte y Useche, ${ }^{15}$

10 Macarena Trujillo, "Misoginia y violencia hacia las mujeres: dimensiones simbólicas del género y del patriarcado", Atenea (Concepción), núm. 519 (junio 2019): 49-64, https://scielo.conicyt.cl/scielo.php?script=sci_art text\&pid=S0718-04622019000100049 (acceso noviembre 15, 2019).

11 Leidy Alvarado Fajardo y Ana Poveda Ortiz, "Violencia intrafamiliar masculina. 'Una realidad silenciosa" (tesis de especialización, Universidad Distrital Francisco José de Caldas, 2018).

12 Adam Baird, "Convertirse en el más malo: trayectorias masculinas de violencia en las pandillas de Medellín", Revista Estudios Socio-Jurídicos 20, núm. 2 (2018): 22, https://revistas.urosario.edu.co/ xml/733/73355715002/index.html (acceso noviembre 15, 2019).

13 Lena Krook y Juliana Restrepo, "Género y violencia política en América Latina. Conceptos, debates y soluciones", Política y Gobierno 13, núm. 1 (enero-junio 2016): 23, https://www.redalyc.org/pdf/603/60343614006. pdf (acceso noviembre 15, 2019).

14 Fabiana Rodríguez, Carolina González y Francisco Messenet, "Sátira política en las elecciones de 1935 y de 2016. Estudio comparativo de representaciones sociales femeninas en Topaze y The Clinic", Comunicación y Medios, núm. 39 (enero-junio 2019): 24, https://revistas.uchile.cl/index.php/RCM/article/view/51961 (acceso noviembre 15, 2019).

15 Carolina Pinzón Estrada et al., "Percepción de la violencia simbólica en estudiantes universitarias. Análisis desde la categoría de género", Ánfora 26, núm. 46 (enero-junio 2019): 89-110. https://doi.org/10.30854/ 
y la tesis de grado de Elejalde y Gómez, ${ }^{16}$ quienes se han ocupado de identificar las formas de violencia contra la mujer en escenarios académicos, principalmente universitarios, y concluyeron que, en estos contextos, las mujeres estudiantes no identifican ni perciben las diferentes violencias que se generan en sus entornos estudiantiles.

Por su parte, el estudio de Elverdin, acerca de la escuela rural, da cuenta de "la relación entre el campo educativo y las diversas concepciones de género que en este tipo de espacios se configuran", ${ }^{17}$ lo que propicia la desigualdad, de un lado, en el binarismo hombre/mujer y, de otro, las acciones pedagógicas que se encaminan para reproducir esta desigualdad en las relaciones.

Gutiérrez y Vega analizan una representación de explotación sexual y violencia que se adelanta en el marco de una celebración estudiantil en México, que incluye elementos como ocultamiento, baile erótico y acoso sexual, y concluyen que esta celebración histórica "es una afirmación complaciente de las creencias y prácticas machistas que legitiman la explotación sexual de las mujeres y una aceptación tácita de sus abusos, los cuales, aunque suelen ser ocultados, sí son reconocidos como una tradición venerable". ${ }^{18}$

Algunos artículos relacionan directamente la violencia simbólica y de género con imposiciones culturales que se reproducen en la televisión, la publicidad y los medios de comunicación, como es el caso de los trabajos adelantados por Martínez, ${ }^{19}$ Gómez ${ }^{20}$ y Alonso, ${ }^{21}$ en los cuales toman fuerza los discursos, los contenidos y las representaciones de estereotipos que se transmiten por estos medios y que justifican

anf.v26.n46.2019.554 (acceso noviembre 15, 2019).

16 Viviana Elejalde e Ivonne Gómez, "Percepciones de las estudiantes de trabajo social frente a la violencia simbólica y su impacto al interior de la universidad como en su vida cotidiana" (tesis de pregrado, Corporación Universitaria Minuto de Dios, 2014), 67.

17 Florencia Elverdin, "Relaciones de género en el campo educativo desde la perspectiva de Bourdieu", De prácticas y discursos 1, núm. 1 (2012): 2, http://biblioteca.clacso.edu.ar/Argentina/ces-unne/20140506094304/ ArtElverdin.pdf (acceso noviembre 15, 2019).

18 Rafael Gutiérrez y Leticia Vega, "La violencia simbólica de la explotación sexual de mujeres en una celebración estudiantil", Salud Mental 37, núm. 4 (julio-agosto 2014): 341, http://www.scielo.org.mx/scielo. php?script=sci_arttext\&pid=S0185-33252014000400008 (acceso noviembre 15, 2019).

19 Julia Martínez, "Violencia simbólica contra las mujeres", Pueblos (2011), http://www.revistapueblos.org/ old/spip.php?article2290 (acceso noviembre 15, 2019).

20 María Gómez, "La violencia de la publicidad contra la mujer", Questiones Publicitarias 1, núm. 20 (2015): 58-72, https://ddd.uab.cat/pub/quepub/quepub_a2015n20/quepub_a2015n20p58.pdf (acceso noviembre 15, 2019).

21 Ana Alonso, coord., Violencia de género y comunicación (Andalucía: Cuadernos Artesanos de Comunicación, 2016). 
la desigualdad, la subordinación y el sostenimiento del imaginario patriarcal en la sociedad. Así mismo, el tratamiento mediático dado a los casos de feminicidios que ocurren puntualmente en Argentina se presentan en el artículo de Sosa y Grosso, ${ }^{22}$ el cual muestra la violencia simbólica en la dicotomía entre lo público y lo privado.

Relacionado con lo anterior, se encuentra un análisis teórico sobre los estereotipos que se asignan a las mujeres, en el que se concluye que: "El grave problema de la violencia es que no sólo deja su impronta en la exterioridad del cuerpo, sino en su interioridad. Cabe cuestionarse si habría violencia simbólica, caso la desnudez y la cabellera estuviesen descorporizados, sin historicidad y contexto". ${ }^{23}$

Según los autores citados, se genera violencia simbólica en contra de las mujeres a partir de las representaciones e imposiciones que sobre el cuerpo, la desnudez y la cabellera se naturalizan para distinguir y diferenciar los géneros, lo que contribuye a la permanencia del poder masculino y a un orden social androcéntrico.

Por otra parte, se identifican tres artículos en los que se analizó la violencia simbólica y las relaciones de dominación por razones del género desde miradas netamente teóricas y conceptuales, como lo expone Posada en su artículo "Sobre Bourdieu, el habitus y la dominación masculina: tres apuntes". ${ }^{24}$ Afirma que la dominación masculina y la violencia simbólica están fundamentadas en las relaciones de poder en el campo social, que se proyectan naturales y "como orden estructurante que se revela en las relaciones más cotidianas entre los sexos". ${ }^{25}$ Merino ${ }^{26}$ analiza las causas de la violencia en contra de las mujeres asociada con el hecho de la subsistencia de relaciones de desigualdad en las estructuras sociales, lo que denomina injusticia estructural. Por último, al caracterizar el feminismo como un campo bourdieuano, Sánchez-Perera analiza las relaciones de poder y describe el reparto desigual del

22 Lorena Sosa y Mariana Grosso, "La prohibición de la violencia simbólica y mediática en la Argentina: ¿superación de la dicotomía público/privada?", Revista Electrónica. Instituto de Investigaciones Ambrosio L. Gioja, núm. 20, (junio-noviembre 2018), http://www.derecho.uba.ar/revistas-digitales/index.php/revistaelectronica-gioja/article/view/368 (acceso noviembre 15, 2019).

23 Carolina Serrano Barquín et al., "Estereotipos de género que fomentan violencia simbólica: desnudez y cabellera", Estudos Feministas 26, núm. 3 (septiembre 2018): 11, https://doi.org/10.1590/1806-9584$2018 v 26 n 344848$ (acceso noviembre 15, 2019).

24 Luisa Posada Kubissa, "Sobre Bourdieu, el habitus y la dominación masculina: tres apuntes", Revista de filosofía, núm. 73, (octubre 2017): 2, https://revistafilosofia.uchile.cl/index.php/RDF/article/view/47737/57429 (acceso noviembre 15, 2019).

25 Posada Kubissa, "Sobre Bourdieu, el habitus", 252.

26 Rubén Merino Obregón, "La comprensión de la violencia de género como injusticia estructural", Cuestiones de género: de la igualdad y la diferencia, núm. 14 (2019): 9-27, http://revpubli.unileon.es/ojs/index.php/ cuestionesdegenero/article/view/5769/4475 (acceso noviembre 15, 2019). 
poder simbólico y la distribución de los capitales en el marco de las discusiones frente a la prostitución y colige que en estas se despliegan mecanismos de censura, que se materializan en la exclusión de las mujeres que ejercen la prostitución. "Esta censura emplea la dominación afectiva, el pánico moral, que evita que ciertas cuestiones se discutan, organizando la agenda y dando preferencia al papel de la prostitución como institución". ${ }^{27}$

Se pueden identificar dos publicaciones enfocadas en analizar la violencia simbólica contra las mujeres en el ámbito de las relaciones de pareja. Así, en la tesis de pregrado de Rivera y Morera ${ }^{28}$ se adelanta un estudio con quince mujeres en la ciudad de Bogotá para identificar la subordinación y las condiciones de inferioridad en las que son puestas las mujeres, producto de construcciones históricas que han configurado una cultura patriarcal que reproduce y naturaliza la violencia, la imposición de roles y la desigualdad entre los géneros. Asimismo, se encuentra el análisis que adelanta Ariza ${ }^{29}$ en la tesis doctoral sobre la violencia en las relaciones de pareja en Medellín, desde un enfoque de salud pública; de identificar las construcciones culturales sobre el género y las representaciones sociales que inciden en el que es tratado por la autora como un problema social en esa ciudad.

Un trabajo que se aparta de los anteriores, en cuanto a las formas y los temas, es el análisis musical a partir del concepto de violencia simbólica de Bourdieu en las canciones de la cantante Paquita la del Barrio. Barrera y Contreras destacan que esta música hace unos llamados a las mujeres y "nos resume la expresión de un conjunto de agravios vividos por generaciones, la construcción de ciertas estrategias de reivindicación femenina, dentro de los referentes de las representaciones de la dominación masculina de las condiciones femenina y masculina". ${ }^{30}$

\footnotetext{
Paula Sánchez-Perera, "Un debate adulterado: distribución del poder simbólico en las disputas feministas en torno a la prostitución", Revista Mediterránea de Comunicación 10, núm. 1 (2019): 143, https://www. mediterranea-comunicacion.org/article/view/2019-v10-nl-debate-adulterado-distribucion-podersimbolico-disputas-feministas-prostitucion (acceso noviembre 15, 2019).

28 Geraldine Rivera y Angie Morera, "Comprensión de la naturalización y reproducción de la violencia contra la mujer. El caso de quince adultas mayores de la ciudad de Bogotá" (tesis de pregrado, Corporación Universitaria Minuto de Dios, 2017).

29 Gladys Ariza, "La violencia en las relaciones de pareja en Medellín y sus representaciones sociales" (tesis doctoral, Universidad Nacional de Colombia, 2011).

30 Dalia Barrera y Sonia Contreras, "Reivindicaciones femeninas, dominación masculina y violencia simbólica en las canciones de Paquita la del Barrio", La ventana 6, núm. 48 (julio-diciembre 2018), 324, http://www. scielo.org.mx/scielo.php?script=sci_arttext\&pid=S1405-94362018000200294\&lng=es\&nrm=is (acceso noviembre 15,2019 ).
} 
Se destaca en este campo —aunque también podría estar incluido en el campo político-el informe Aniquilar la diferencia: lesbianas, gays, bisexuales y transgeneristas en el marco del conflicto armado colombiano, ${ }^{31}$ del Centro Nacional de Memoria Histórica, en el cual se aborda la categoría de violencia simbólica desde la obra Sentido práctico, de Bourdieu; en particular, plantea que la violencia simbólica se practica de diferentes maneras, todas ellas con un elemento en común: reforzar la hegemonía heteropatriarcal y el binarismo de género hombres/mujeres. De acuerdo con el informe, esta violencia, ha servido para definir ese lugar marginal del que, en muchas ocasiones, los sujetos no son conscientes, en tanto que:

En muchos casos, estas modalidades de violencia están acompañadas de tortura y de altas dosis de sevicia. Queda para la memoria histórica del país, que estas violencias son cometidas por distintos grupos armados, tanto legales (fuerzas armadas y Policía) como ilegales (guerrillas, paramilitares, grupos de posdesmovilización paramilitar, y en algunos casos, grupos al servicio del narcotráfico). ${ }^{32}$

De las revisiones expuestas se puede identificar que, en el tópico de violencia simbólica y género, el principal autor citado es Pierre Bourdieu, en especial sus obras La dominación masculina y La reproducción.

\subsection{Violencia simbólica en el campo social}

De acuerdo con González Ochoa, "la noción de violencia simbólica remite a la interiorización por parte de los agentes del dominio social inherente a la posición que ocupan en un campo dado y, en general, a su posición social"; 33 este juego de dominios comprende tanto los sistemas de relaciones de poder como un sistema de relaciones de significado. Este doble aspecto permite ver la sociedad, desde afuera, como una estructura objetiva cuyas articulaciones pueden ser observadas materialmente, medidas y trazadas independientemente de las representaciones de los que viven en ella. ${ }^{34}$

31 Centro Nacional de Memoria Histórica, Aniquilar la diferencia: lesbianas, gays, bisexuales y transgeneristas en el marco del conflicto armado colombiano (Bogotá: CNMH, UARIV, USAID, OIM, 2015).

32 Centro Nacional de Memoria Histórica, Aniquilar la diferencia: lesbianas, 34.

33 César González Ochoa, "Una teoría de la sociedad", Cultura y Representaciones Sociales 12, núm. 24 (marzo 2018): 278, http://www.scielo.org.mx/pdf/crs/v12n24/2007-8110-crs-12-24-273.pdf (acceso noviembre 15, 2019).

34 González Ochoa, "Una teoría de la sociedad", 278. 
Después del de género, en este campo fue en el que más publicaciones se encontraron en los últimos diez años. Aquí fueron identificados diversos estudios que podrían ubicarse en otros campos o subcampos, pero se decidió unificarlos en este por la prevalencia en sus reflexiones sobre lo social y lo antropológico y porque permiten comprender de alguna manera los dos sistemas de relaciones mencionados. Se analizó, por ejemplo, el artículo "Ser diferente en un mundo de semejanzas: ensayo sobre la dimensión simbólica de la vulnerabilidad", ${ }^{35}$ publicado por la revista Íconos; el autor "se apoya en los conceptos de poder simbólico, violencia simbólica y veredicto social, para perfilar una teoría de la vulnerabilidad simbólica, que es en sí una amenaza al derecho a no ser avergonzado, injuriado o lastimado". ${ }^{36}$ De igual manera, pone como ejemplos casos de misoginia y violencia contra la mujer en el espacio público en México, y de racismo, que se evidencia en las dificultades de acceso a ciertos niveles de escolaridad y empleo, por causa del color de piel. En últimas, esta "dimensión simbólica de la vulnerabilidad radica en ser portador de cierta característica socialmente estigmatizada, que obstaculiza el acceso a ciertos activos — capital escolar, por ejemplo— que son fundamentales para contar con oportunidades para hacer su vida". ${ }^{37}$

Una reciente tesis de grado, titulada Cuerpos que se resisten a ser borrados: acompañamiento psicosocial a personas que habitan la calle ${ }^{38}$ toma aspectos metodológicos de Bourdieu y conceptos esenciales como habitus, que se explican como el producto de unas condiciones de existencia diferentes, en el que se manifiestan prácticas identitarias y estilos de vida en donde yacen pronunciamientos cercanos a la división de clases sociales y el reconocimiento inconsciente de estos elementos. Allí se decanta una violencia simbólica, resultado del afán constante por encajar en el cuerpo perfecto, que presiona todas aquellas figuras corporales que tienen cualidades lejanas al ideal y, en ese caso, deberían hacer lo posible por llegar al ideal o serán víctimas de una violencia. En sí, una violencia silenciosa y que resulta indiscriminada, porque las personas tienden a ignorar su carácter violento. ${ }^{39}$

\footnotetext{
35 Ducange Médor Bertho, "Ser diferente en un mundo de semejanzas: ensayo sobre la dimensión simbólica de la vulnerabilidad", Iconos, núm. 64 (mayo 2019): 139-157, https://revistas.flacsoandes.edu.ec/iconos/ article/view/3144 (acceso noviembre 15, 2019).

36 Médor Bertho, "Ser diferente en un mundo de semejanzas", 139.

37 Médor Bertho, "Ser diferente en un mundo de semejanzas", 145.

38 Stephania Rincón, "Cuerpos que se resisten a ser borrados: acompañamiento psicosocial a personas que habitan la calle" (tesis de pregrado, Corporación Universitaria Minuto de Dios, 2017).

39 David Le Breton, Antropología del cuerpo y modernidad (Buenos Aires: Ediciones Nueva Visión, 2002), 134.
} 
En relación con la violencia sobre personas extranjeras cabe destacar el trabajo de Cleveland, Kronick Hanna y Gros Cécile Rousseau, ${ }^{40}$ cuyos resultados mostraron que los solicitantes de asilo expresaron conmoción y humillación al ser tratados como criminales. Encontraron, además, que la detención, incluso durante breves períodos en condiciones relativamente adecuadas, fue perjudicial para la salud mental de los solicitantes de asilo y en varias ocasiones desencadenó retraumatizaciones. Este impacto adverso parece ser en gran parte atribuible al efecto combinado de dos factores: violencia simbólica y desempoderamiento.

De igual manera, con una metodología cualitativa consistente en catorce grupos focales, González y Plotnik ${ }^{41}$ encontraron que la violencia simbólica hacia los migrantes internacionales en el contexto escolar y judicial, se presenta en tres ejes: la invisibilización, el migrante como amenaza-enemigo y el migrante como invasor.

Para cerrar con los hallazgos en este campo, se encontró una reciente publicación sobre la violencia en la cárcel, titulada La función social punitiva en Iberoamérica. Circunstancias globales y locales, ${ }^{42}$ que aborda algunas ideas sobre la violencia simbólica perpetuada en las cárceles de Iberoamérica y plantea críticas similares a las que hace Wacquant a lo largo de su obra. También hace referencia al hostigamiento de personas pobres en los espacios públicos y a su encarcelamiento, con lo que pone el problema del delito y su contención en un marco eminentemente represivo y de mano dura; sin embargo, dichas prácticas punitivas suelen terminar produciendo una reacción contraria a la esperada, como ocurre con todo exceso de autoritarismo e intolerancia. ${ }^{43}$ Es relevante destacar esta publicación, puesto que la expectativa frente a las publicaciones en el campo criminológico y penitenciario eran altas, pero después de elaborar el estado del arte, encontramos que los resultados al respecto eran escasos.

40 Janet Cleveland et al. "Symbolic Violence and Disempowerment as Factors in the Adverse Impact of Immigration Detention on Adult Asylum Seekers' Mental Health International Journal of Public Health", Social Science E Medicine 70, núm 12 (junio 2018), https://ideas.repec.org/a/spr/ijphth/v63y2018i8d10.1007_s00038018-1121-7.html (acceso noviembre 15, 2019).

41 Anahí González y Gabriela Plotnik, "Nosotros-otros', violencia simbólica y representaciones sociales sobre el migrante internacional. Un análisis en las instituciones educativa y judicial en la ciudad de Buenos Aires y Gran Buenos Aires", Argumentos, núm. 15 (noviembre 2013), http://biblioteca.clacso.edu.ar/Argentina/ iigg-uba/20140625053517/argumentos15-7.pdf (acceso noviembre 15, 2019).

42 Fernando Gil Villa, "La función social punitiva en Iberoamérica. Circunstancias globales y locales", URVIO. Revista Latinoamericana de Estudios de Seguridad, núm. 24 (2019), https://revistas.flacsoandes.edu.ec/urvio/ article/view/376245762 (acceso noviembre 15, 2019).

43 Gil Villa, "La función social punitiva en Iberoamérica", 40. 


\subsection{Violencia simbólica en el campo político}

Como se mencionó, en este campo se hallaron catorce publicaciones, de las cuales cinco, abordan lo político en relación con el conflicto armado e incorporan a su vez el concepto de violencia simbólica. Por ejemplo, Pérez plantea:

La falta de discusión sobre la noción de violencia y sobre las implicaciones que tienen para los diferentes actores, conduce a la configuración de una tradición de pensamiento con base en una perspectiva que enfatiza algunos aspectos y desconoce o invisibiliza otros. ${ }^{44}$

En otra publicación se encontró el abordaje de la categoría de violencia simbólica desde un macromolde crítico, que se centró en el proceso histórico que ha configurado el conflicto armado interno, a partir de la época colonial. Serra asegura:

En Latinoamérica, la conquista representó un proceso de deshumanización y degradación de las poblaciones indígenas y autóctonas que, en concomitancia con la organización política, social y sobre todo territorial impuestas por los conquistadores en el continente, tuvieron un rol determinante tanto en el surgimiento como en el desarrollo de los conflictos armados que se han presentado y se presentan actualmente en estos países. ${ }^{45}$

Asimismo, Céspedes acoge la perspectiva teórica de Pierre Bourdieu y su triada de habitus, campo social y capital, para explicar, desde una mixtura del enfoque histórico-sociológico con los estudios psicosociales, cómo la construcción de la masculinidad en Colombia tiene una relación estrecha con la vía armada, es decir:

[...] la virilidad, se asocia con las armas, la guerra y la violencia, en tanto el predominio de valores guerreristas, sumado a las dificultades en el acceso de capital económico y social en zonas de conflicto; lo que dio cabida a la vinculación de la vía armada como estilo de vida en Colombia. ${ }^{46}$

44 Andrea Pérez Fonseca, "La clasificación social del otro: formas de nombrar la 'peligrosidad' en el marco del conflicto armado colombiano", Análisis Político 28, núm. 84 (2015): 68, https://revistas.unal.edu.co/ index.php/anpol/article/view/54639/54090 (acceso noviembre 15, 2019).

45 David Serra, "Herencias coloniales y violencia simbólica en el conflicto armado peruano". Cuadernos de Filosofía Latinoamericana 35, núm. 113 (2015): 181, https://revistas.usantotomas.edu.co/index.php/cfla/ article/view/2239/2585 (acceso noviembre 15, 2019).

46 Sandra Céspedes, "Disposiciones, trayectorias e imaginarios sociales de Estado y ciudadanía en el proceso de reintegración de guerrilleros y paramilitares en Colombia", Revista Colombiana de Sociología 38, núm. 1 (mayo 2015), 186, http://www.scielo.org.co/pdf/rcs/v38nl/v38nla10.pdf (acceso noviembre 15, 2019). 
De forma similar, en el artículo "Órdenes locales y conflicto armado. Una metodología comparada"47 se utilizan las nociones de agencia, campos y habitus con base en Bourdieu, ${ }^{48}$ como elementos de apoyo en la comparación de las reconfiguraciones de órdenes locales en medio del conflicto armado. Aunque los autores refieren el concepto de violencia simbólica, prefieren emplear el concepto de "conflicto armado entre actores armados" que, en el caso colombiano, puede tener distintas motivaciones, en los marcos de procesos de formación de Estado. Como resultado de esta investigación se presentan algunas tablas comparativas que permiten, en primer lugar, identificar y analizar similitudes y diferencias de las aglomeraciones complejas de los tipos de orden local según la relación entre la agencia de los civiles (que pueden ser de sometimiento, acomodamiento, solidaridad o resistencia) y la coerción de los actores armados (que puede ser armada o política); en segundo lugar, examinar las variaciones de distintos casos dentro de un mismo tipo de orden local. No obstante, se aclara, este artículo forma parte de una serie de seis, desarrollados por los equipos de los centros de investigación INER, de la Universidad de Antioquia; Cidse, de la Universidad del Valle, y Cinep, de Bogotá, en el marco del proyecto de investigación Órdenes locales en reconfiguración: de regulaciones, acomodos y resistencias en regiones de intenso conflicto violento 1991-2010. Una investigación comparada, con el cual se pretende resaltar el valor que tiene la construcción de estas tipologías para la reflexión teórica, más allá de las exigencias que implican estos estudios comparativos.

Para terminar con las publicaciones analizadas en este campo, se encontró una tesis de pregrado en ciencias políticas de la Universidad Javeriana, en la que se hace la diferenciación entre este tipo de violencia y la violencia estructural, argumentando que muchas veces "la violencia simbólica no siempre es un reflejo de la violencia estructural, muchas veces se constituye en una circunstancia propiciatoria de la violencia directa y el mantenimiento de condiciones estructurales de dominación y

47 Clara García et al., "Órdenes locales y conflicto armado: una metodología comparada", Análisis Político 27, núm. 81 (2014): 107-121. https://revistas.unal.edu.co/index.php/anpol/article/view/45762 (acceso noviembre 15, 2019).

48 En cuanto a los órdenes locales y al conflicto armado en Medellín existen dos publicaciones que se concentraron en la dimensión simbólica y en el ejercicio de la violencia por parte de los agentes criminales. Si bien no abordaron la obra de Pierre Bourdieu, sí consideraron el papel de los grupos criminales en la instauración de los órdenes en el ámbito local y la relación práctica y simbólica entre las comunidades y los criminales. Luis Dávila, "Violencia urbana, conflicto y crimen en Medellín: una revisión de las publicaciones académicas al respecto", Criminalidad 58, núm. 2 (abril 2016): xx, http://www.scielo.org.co/pdf/ crim/v58n2/v58n2a03.pdf (acceso noviembre 15, 2019); Luis Dávila, Reglas, crimen y orden. Un estudio sobre la seguridad en Medellin (Medellín: La Carreta Editores E. U., 2018). 
sometimiento". ${ }^{49}$ En este trabajo, el autor retoma la definición de violencia simbólica de la obra de Bourdieu de mediados de la década del noventa y la complementa con la noción de violencia cultural construida por Galtung a finales de la década del ochenta.

\subsection{Violencia simbólica en el campo educativo y pedagógico}

De acuerdo con Uribe y Sánchez, el orden de la violencia simbólica "conforma una serie de prejuicios y encasillamientos que se traducen en relaciones de poder, que son sustentadas por reglas —explícitas o implícitas— legitimadas en el imaginario colectivo". ${ }^{50}$ Por tanto, pensar en el contexto escolar significa situar los discursos pedagógicos que consolidan el capital cultural impuesto de forma autoritaria o persuasiva por parte de los docentes hacia los estudiantes y que terminan reproduciendo la estructura social.

Para Bourdieu y Passeron, la estructura y el funcionamiento de la enseñanza institucionalizada responde a la necesidad de producir las condiciones institucionales que le son necesarias para el ejercicio de su función (su propia conservación) y la reproducción de un orden cultural de la que no es productora. En este sentido, la reproducción en el ámbito del sistema educativo se refiere a los mecanismos por los cuales "la institución escolar contribuye a reproducir la distribución del capital cultural y, con ello, la estructura del espacio social" ${ }^{51}$ De este modo, el sistema escolar es un espacio de luchas que sirve a la reproducción de la estructura social y que, a su vez, es capaz de generar transformaciones. Con el fin de vencer las resistencias a su lógica, el sistema escolar utiliza la "violencia simbólica", referida a la imposición de una arbitrariedad cultural e inculcación de una ideología que preserva y reproduce las relaciones de fuerza entre las clases sociales, traducidas en formas de dominio mediante la acción pedagógica. ${ }^{52}$

La acción pedagógica, difusa o institucionalizada, es conceptualizada como una forma sutil de violencia simbólica persistente orientada a producir un habitus mediante

49 Iván Andrés Marín Mesa, "Análisis de la violencia simbólica en el conflicto armado en Colombia" (tesis de pregrado, Pontificia Universidad Javeriana, 2013), 4.

50 Bertha Alcántara y Luz Ibarra, "Violencia simbólica y reflexividad en el trabajo de campo", Inventio, la génesis de la cultura universitaria en Morelos 13, núm. 30 (2017): 22, http://inventio.uaem.mx/index.php/ inventio/article/view/267/895 (acceso noviembre 15, 2019).

51 Pierre Bourdieu y Jean Passeron, La reproducción. Elementos para una teoría del sistema de enseñanza (Barcelona: Laia, S. A., 1997), 125

52 Pierre Bourdieu y Jean Passeron, La reproducción. Elementos para una teoría del sistema de enseñanza (Madrid: Fontamara, 1996), 36. 
la interiorización de un arbitrario cultural "capaz de perpetuarse y perpetuar en las prácticas los principios de la arbitrariedad cultural interiorizada". ${ }^{53}$

Por otra parte, el texto "Violencia e inseguridad en las instituciones educativas: jóvenes en la mira de una sociedad del miedo" 54 hace referencia a una violencia ejercida en la cotidianidad, reflejada en la mala comunicación entre los actores educativos, que afecta las relaciones interpersonales y llega a producir una segregación en la cultura global de una institución educativa. Al no restringirse al ámbito delictivo y criminal, esta conceptualización logra ampliar aún más el fenómeno de la violencia en los espacios educativos e irrumpe de alguna manera en la convivencia social. Esta violencia de carácter institucional también se podría definir como simbólica, en palabras de Pierre Bourdieu, pues la idea de dominación y poder en las prácticas educativas están implícitas. Al respecto, sostiene Farías:

Aquí están muy presentes relaciones de interacción simbólica, como plantean Mead, Blummer y otros, ya que el intercambio de gestos, miradas, es decir, de símbolos en los vínculos sociales, generan muchas veces actos violentos de carácter cotidiano. Por consiguiente, si hablamos de prácticas que se ejercen simbólicamente en la cotidiana, vemos la necesidad de problematizar la violencia dentro de las aulas como un tema a resolver entre el colectivo educativo, y no simplemente verlo como algo que ya está instituido naturalmente y con lo que hay que convivir irremediablemente. ${ }^{55}$

En el artículo "Conflicto y educación superior: narrativas y vivencias de jóvenes universitarios estudiantes de ciencias sociales y humanas" ${ }^{\prime 56}$ la educación se presenta como lugar de particularidades, escenario donde surgen manifestaciones de violencia simbólica que hacen notoria la emergencia de múltiples desencuentros entre los estudiantes y generan situaciones de tensión por posiciones contrarias, que suelen

53 Pierre Bourdieu y Jean Passeron, La reproducción. Elementos para una teoría del sistema de enseñanza. Madrid: Popular, 2002), 47.

54 Leonel Farías, "Violencia e inseguridad en las instituciones educativas: jóvenes en la mira de una sociedad del miedo", Cuadernos de Educación y Desarrollo (2013): 1-8, https://pdfs.semanticscholar.org/83 06/4dac3845356684467df67e93dab57a5ffa00.pdf?_ga=2.47038439.1190364674.1586767786232721732.1586767786 (acceso noviembre 15, 2019).

55 Farías, "Violencia e inseguridad en las instituciones educativas: jóvenes", 5.

56 Ana Arias Cardona y Mariana Arias Gómez, "Conflicto y educación superior: narrativas y vivencias de jóvenes universitarios estudiantes de ciencias sociales y humanas", Revista CES Psicología 11, núm. 1 (septiembre 2017): 57, http://revistas.ces.edu.co/index.php/psicologia/article/view/3951 (acceso noviembre 15, 2019). 
desembocar en expresiones como el sarcasmo, la discriminación, la evitación y la desidia, entre otras:

El conflicto en los universitarios es interpretado como violencia física. Estos estudiantes perciben que los asuntos académicos son la principal dificultad en sus relaciones interpersonales, refieren que entablan pocas relaciones con personas diferentes a sí mismos en tanto opciones políticas, religiosas, sexuales, etc., expresan que banalizan las manifestaciones violentas y admiten que existe una fuerte tendencia a que después de un conflicto, se produzca una ruptura de la relación que estaba en juego. ${ }^{57}$

Estos aportes son trabajados alrededor de nociones ligadas al concepto de violencia simbólica para explicar la reproducción de lo instituido, generada en la invisibilización/naturalización producida en el discurso, en la percepción y en las acciones del proyecto escolar moderno basado en la disciplina y el gobierno de los sujetos estudiantiles. ${ }^{58}$

Violencia simbólica es aquella en la cual las víctimas desconocen la ilegitimidad de las asimetrías implicadas en una relación, la consienten como necesaria y no perciben la arbitrariedad del ejercicio del poder y la dominación violenta de los victimarios. Por eso, importa indagar los sentidos del nombramiento de la misma en los espacios escolares por parte de las voces y desde las perspectivas de los agentes educativos, así como indagar la importancia de lo que se omite o permanece silenciado.

\section{Discusiones y conclusiones}

Elaborar un estado del arte permite identificar asuntos como tendencias de publicación, áreas temáticas de interés, exploraciones conceptuales y empíricas, y otros asuntos inherentes al desarrollo teórico de una categoría en particular. De cierta forma, permite tomar el pulso de una serie de discusiones y dilemas e ilustrar posibles ejes o aristas de crecimiento o evolución conceptual. Para este cometido, como puede verse en el presente artículo, la violencia simbólica ha tenido permutaciones en el contexto latinoamericano. Entre ellas, es resaltable la predominancia del concepto

\footnotetext{
Arias Cardona y Arias Gómez, "Conflicto y educación superior: narrativas y vivencias", 57.

58 Cristina Erausquin y Carolina Dome, "Violencia simbólica, violencia institucional o invisibilidad de la mediación del sistema societal de la actividad escolar: posicionamiento ético del psicólogo en educación" (ponencia presentada en el I Congreso internacional de victimología, Ensenada, 24-26 de agosto, 2016) https://www.aacademica.org/cristina.erausquin/23.pdf (acceso noviembre 15, 2019).
} 
en relación con estudios de género, mientras que en el campo pedagógico puede ubicarse un momento o período de gestación epistemológica, para lo cual también es pertinente revisar las herramientas y la metodología empleada.

Para los aprendizajes y recorridos en la elaboración de este ejercicio, resulta meritoria la ayuda que herramientas como el ATLAS.ti y otras aplicaciones de software especializadas en el análisis cualitativo de datos pueden proveer para la organización de información. Debido al creciente repertorio de referencias bibliográficas disponibles en medios virtuales, optar por herramientas de entrada como estas, apoya la sistematización como un proceso permanente de construcción de conocimiento socialmente relevante, así como la optimización en el procesamiento de la información y su posterior análisis y trabajo cualitativo por parte de todo un equipo de trabajo compuesto por múltiples actores con diferentes concepciones, miradas, apreciaciones y acercamientos a una obra o categoría en particular, como en el presente caso con los trabajos desarrollados en el campo de la violencia simbólica devenida de Pierre Bourdieu.

La obra de Bourdieu, en especial su contribución a la sociología reflexiva con su teoría de la violencia simbólica, ha resultado de gran interés en algunos países latinoamericanos en los que, de acuerdo con los hallazgos, han primado los acercamientos a esta categoría en los estudios de género y feminismo. Allí, sus planteamientos sobre la dominación masculina y sus múltiples textos e investigaciones sobre esta han tenido gran influencia. En segundo lugar, los estudios ligados a diversos asuntos sociológicos y antropológicos que ponen el foco en poblaciones vulnerables como migrantes, habitantes de calle y población privada de la libertad; los estudios sociopolíticos alrededor de los conflictos armados, y otras investigaciones orientadas al contexto educativo y pedagógico también resultaron ser de los más concurridos a la hora de tener en cuenta las teorías y apuestas metodológicas de Pierre Bourdieu y de tomar, para su argumentación y análisis, esta categoría de violencia simbólica, la cual fungió como hilo conductor del presente trabajo. Con todo, la conclusión debe ser que el concepto de violencia simbólica sigue vigente en América Latina y, de hecho, parece que está en proceso de popularizarse como herramienta teórica e investigativa: en los últimos tres años se presenta el mayor número de apariciones, lo cual desvirtúa algunas hipótesis del equipo que consideraba que la obra de Bourdieu y sus conceptos fundamentales habían caído en desuso. 
Aquella marcada relación entre Bourdieu y los estudios contemporáneos de género puede deberse, como han argumentado Maldonado Gómez ${ }^{59} \mathrm{o}$, más recientemente, Posada Kubissa, ${ }^{60}$ entre otros, al bagaje histórico del concepto en sí mismo, puesto que uno de los puntos de partida de Bourdieu para ilustrar esta categoría suele asociarse con las relaciones dicotómicas de género construidas histórica y culturalmente en el mundo occidental moderno. Por otro lado, esta relación no suele manifestarse tan fuertemente en los otros campos identificados, en tanto los autores de los estudios y las investigaciones citadas no siempre recurrían a Bourdieu para argumentar sus pesquisas; en algunos casos, su acercamiento al concepto era propiciado por la facilidad de este para identificar situaciones de vulneración social, sin establecer como una condición sine qua non el recurrir a la triada conceptual de Bourdieu. Es decir, si bien la obra de Bourdieu aún se manifiesta reiteradamente en los estudios de género, en otros campos del saber parece haberse desarrollado una suerte de independencia epistemológica del concepto, desligado de uno de sus principales referentes y con unas nuevas concepciones desde aproximaciones empíricas particulares, al menos en el caso del contexto latinoamericano.

En la publicación de Trujillo ${ }^{61}$ aparece, como elemento clave para enfrentar la violencia simbólica, el cuestionar por medio de nuevas formas de pensamiento/ conocimiento, para ver la realidad más allá de las matrices de percepción patriarcal, los mitos y las narrativas, como las de Teogonía y el Génesis, en las cuales el imaginario sobre la mujer es infravalorado, lo que naturaliza la dominación y la violencia por parte del hombre.

El concepto de violencia simbólica de Pierre Bourdieu ha sido soporte teórico de las relaciones de desigualdad y de poder que se presentan en diversos campos en la estructura social; es por ello que puede referirse que este no es un concepto neutral: es un concepto político que, tal vez sin que el autor se lo proponga, ha permitido, como en el caso de los estudios de género, desarrollar teorías que desvelan las violencias que se presentan en razón de las asimetrías por los estatus asignados a cada uno de los sexos en los intercambios simbólicos, así como en las tareas diferenciadas y repartidas según el sexo, las cuales son producto de las construcciones culturales que son inculcadas, por ejemplo, desde la familia y la escuela.

59 María Maldonado Gómez, "Reseña de 'La dominación masculina' de Pierre Bourdieu", Sociedad y economía, núm. 4 (abril 2003): 69-74, https://www.redalyc.org/pdf/996/99617936012.pdf (acceso noviembre 15, 2019).

60 Posada Kubissa, "Sobre Bourdieu, el habitus y la dominación", 251-257.

61 Trujillo, "Misoginia y violencia hacia las mujeres", 62. 
Se considera relevante el aprovechamiento teórico que se ha hecho de los conceptos de dominación masculina y violencia simbólica desde la perspectiva de Bourdieu en variedad de investigaciones que buscan visibilizar y reivindicar los derechos de la población LGBTI o de las personas con identidad de género y orientaciones sexuales no hegemónicas (no binarias), a partir de sus comprensiones como movimiento o como víctimas desde enfoques diferenciales de género o interseccionales.

La teoría bourdiana contribuye a la reflexión sobre el sentido epistemológico de la escuela y la pedagogía, al identificar que los actores escolares, con sus habitus, son portadores de comportamientos y acciones que transgreden el orden establecido en las instancias del entramado institucional Estado-escuela-familia, en el que el concepto de poder y las relaciones de poder se presentan como resultado del habitus que cada uno de los agentes posee, se manifiesta en el actuar cotidiano escolar y se reproduce en todas las esferas de la cultura y la sociedad. En este sentido, los estudios analizados sobre violencia simbólica en el campo educativo y pedagógico develan un abordaje teórico centrado únicamente en las relaciones de autoridad que ejercen docentes y directivos hacia estudiantes, con lo cual se desconoce la multidimensionalidad de una lectura abierta, crítica y compleja del fenómeno, así como las posibilidades de interpretación de la violencia simbólica en el marco de un escenario social que desborda los límites de la institución educativa y que incluye la presencia influyente y determinante de otros actores de la violencia y no solo la mirada hegemónica del victimario y la víctima.

Este panorama expresa la vigencia y la pertinencia del aporte epistemológico y los posteriores desarrollos teóricos de la obra de Bourdieu, en el sentido de que componen un ámbito de estudio que, como ya se dijo, está lejos de la pretensión absolutista. En definitiva, ofrece una ventana de observación acerca de cómo se establecen las relaciones de fuerza y dominación en distintos contextos que se convierten en exploraciones, con las que también se debe tener cuidado porque se corre el riesgo de exigirle al concepto explicaciones que podría no dar, así que este artículo se convierte en un aporte para explorar el concepto y sus posibilidades metodológicas y prácticas. En cuanto a vacíos, sorprende la falta de trabajos que traten el concepto de violencia simbólica en el ámbito jurídico y penitenciario.

Respecto al interés especial que se tenía — debido a lo que se pretende hacer más adelante en el marco del programa del que parte esta investigación — de indagar por estudios cuyo territorio de análisis fuera Medellín, solo cinco publicaciones de las encontradas abordaron la categoría de violencia simbólica. No obstante, se hallaron 
catorce publicaciones cuyo territorio de análisis fue Colombia. Así las cosas, se pueden determinar las categorías sobre las cuales se enmarca la violencia simbólica en Colombia: la primera es un contexto urbano, donde se define la violencia desde un punto de vista sistemático y reproducido por la sociedad misma y, la segunda, desde los territorios rurales, donde convergen situaciones como la falta de presencia del Estado — que configura lógicas de acción que no responden a las dinámicas de un Estado social, democrático y de derecho-, así como el conflicto sociopolítico y armado que desde hace décadas ha afectado principalmente a estas zonas del país y ha generado graves violaciones a los derechos humanos, lo que hace que el contexto sociopolítico de la región sea el punto de partida para la definición de la violencia simbólica en los territorios rurales.

Los develamientos descritos no son más que un acercamiento a la practicidad de una categoría traducida en reflexión epistemológica, es decir, a la aplicación práctica para la que ha servido la violencia simbólica en el contexto latinoamericano en la última década. En esa medida, es posible observar una categoría que hoy suscita asuntos estructurales considerados desde su concepción para encarar situaciones socialmente sensibles y que permiten, de manera directa e indirecta, revisar las relaciones de dominación latentes en el aparato estatal y cultural al que se someten diversas sociedades, incluso la colombiana. Queda la inquietud en el equipo de investigación sobre cuán dinámicas y manejables pueden ser las teorías de Bourdieu si son llevadas a enfoques donde se privilegien las miradas hacia el interior del ser humano — de los sujetos—, es decir, más agencialistas, subjetivas, ideacionales, pues en su aplicación concreta, se tienden a facilitar mucho más las descripciones, explicaciones e interpretaciones, en una perspectiva más estructuralista, de la que ni siquiera su concepción de agente y de habitus pareciera desligarse.

Ante este panorama, se suscitan múltiples dilemas, como la dependencia de la categoría en cuestión en relación con su autor originario o la profundidad con la que estos estudios son abordados desde aristas distintas a los estudios de género. En otras palabras, la evolución de la categoría, en contraposición con su concepción primigenia, se configura hoy como un punto de discusión que trasciende el campo de análisis sociológico y configura un llamado para la academia a revisar, repensar y reevaluar aquellos elementos que ha conjugado para el estudio de situaciones socialmente sensibles, así como los rincones hacia donde estos pueden perfilarse y los campos de exploración empírica para su aplicación. 


\section{Referencias}

Alcántara, Bertha y Luz Ibarra. "Violencia simbólica y reflexividad en el trabajo de campo". Inventio, la génesis de la cultura universitaria en Morelos 13, núm. 30 (2017): 21-27. http://inventio.uaem.mx/index.php/inventio/article/view/267/895 (acceso noviembre 15, 2019).

Alonso, Ana, coord. Violencia de género y comunicación. Andalucía: Cuadernos Artesanos de Comunicación, 2016.

Alvarado Fajardo, Leidy y Ana Poveda Ortiz. "Violencia intrafamiliar masculina. 'Una realidad silenciosa". Tesis de especialización, Universidad Distrital Francisco José de Caldas, 2018.

Arias Cardona, Ana y Mariana Arias Gómez. "Conflicto y educación superior: narrativas y vivencias de jóvenes universitarios estudiantes de ciencias sociales y humanas". Revista CES Psicología 11, núm. 1 (septiembre 2017): 56-68. http://revistas.ces.edu. co/index.php/psicologia/article/view/3951 (acceso noviembre 15, 2019).

Ariza, Gladys. "La violencia en las relaciones de pareja en Medellín y sus representaciones sociales". Tesis doctoral, Universidad Nacional de Colombia, 2011.

Baird, Adam. "Convertirse en el más malo: trayectorias masculinas de violencia en las pandillas de Medellín". Revista Estudios Socio-Jurídicos 20, núm. 2 (2018): 9-48. https://revistas. urosario.edu.co/xml/733/73355715002/index.html (acceso noviembre 15, 2019).

Barrera, Dalia y Sonia Contreras. "Reivindicaciones femeninas, dominación masculina y violencia simbólica en las canciones de Paquita la del Barrio". La ventana 6, núm. 48 (julio-diciembre 2018), 294-326. http://www.scielo.org.mx/scielo. php?script=sci_arttext\&pid=S1405-94362018000200294\&lng=es\&nrm=is (acceso noviembre 15, 2019).

Bourdieu, Pierre y Jean Passeron. La reproducción. Elementos para una teoría del sistema de enseñanza. Madrid: Fontamara, 1996.

Bourdieu, Pierre y Jean Passeron. La reproducción. Elementos para una teoría del sistema de enseñanza. Madrid: Popular, 2002.

Bourdieu, Pierre y Jean Passeron. La reproducción. Elementos para una teoría del sistema de enseñanza. Barcelona: Laia S. A., 1997.

Bourdieu, Pierre y Loïc Wacquant. Una invitación a la sociología reflexiva. Buenos Aires: Siglo XXI Editores, 2005.

Bourdieu, Pierre. "Symbolic Violence". Revista Latina de Sociología, núm. 2 (2012): 1-4. http://hdl.handle.net/2183/12136 (acceso noviembre 15, 2019).

Bourdieu, Pierre. Bosquejo de una teoría de la práctica. Buenos Aires: Prometeo Libros, 2012. Bourdieu, Pierre. El sentido práctico. Buenos Aires: Siglo XXI Editores, 2007.

Bourdieu, Pierre. Razones prácticas. Sobre la teoría de la acción. Barcelona: Anagrama, 1997. 
Cendales, Andrés. "Pensando con Bourdieu contra Bourdieu: una crítica metodológica del mercado lingüístico". Cuadernos de Economía 30, núm. 54 (2011): 193-225. https:// revistas.unal.edu.co/index.php/ceconomia/article/view/24137 (acceso noviembre 15, 2019).

Centro Nacional de Memoria Histórica. Aniquilar la diferencia: lesbianas, gays, bisexuales y transgeneristas en el marco del conflicto armado colombiano. Bogotá: CNMH, UARIV, USAID, OIM, 2015.

Céspedes, Sandra. "Disposiciones, trayectorias e imaginarios sociales de Estado y ciudadanía en el proceso de reintegración de guerrilleros y paramilitares en Colombia". Revista Colombiana de Sociología 38, núm. 1 (mayo 2015), 185-209. http://www.scielo.org. co/pdf/rcs/v38nl/v38nlal0.pdf (acceso noviembre 15, 2019).

Cleveland, Janet, Rachel Kronick, Hanna Gros y Cécile Rousseau. "Symbolic Violence and Disempowerment as Factors in the Adverse Impact of Immigration Detention on Adult Asylum Seekers' Mental Health International Journal of Public Health". Social Science \& Medicine 70, núm. 12 (junio 2018), 2070-2079. https://ideas.repec.org/a/spr/ijphth/ v63y2018i8d10.1007_s00038-018-1121-7.html (acceso noviembre 15, 2019).

Corcuff, Philippe. Las nuevas sociologías. Principales corrientes y debates, 1980-2010. Buenos Aires: Siglo XXI editores, 2013.

Dávila, Luis. "Violencia urbana, conflicto y crimen en Medellín: una revisión de las publicaciones académicas al respecto". Criminalidad 58, núm. 2(abril 2016): 107-121. http://www.scielo.org.co/pdf/crim/v58n2/v58n2a03.pdf (acceso noviembre 15, 2019).

Dávila, Luis. Reglas, crimen y orden. Un estudio sobre la seguridad en Medellín. Medellín: La Carreta Editores E. U., 2018.

Elejalde, Viviana e Ivonne Gómez. "Percepciones de las estudiantes de trabajo social frente a la violencia simbólica y su impacto al interior de la universidad como en su vida cotidiana”. Tesis de pregrado, Corporación Universitaria Minuto de Dios, 2014.

Elverdin, Florencia. "Relaciones de género en el campo educativo desde la perspectiva de Bourdieu”. De prácticas y discursos 1, núm. 1 (2012): 1-15. http://biblioteca.clacso. edu.ar/Argentina/ces-unne/20140506094304/ArtElverdin.pdf (acceso noviembre 15, 2019).

Erausquin, Cristina y Carolina Dome. "Violencia simbólica, violencia institucional o invisibilidad de la mediación del sistema societal de la actividad escolar: posicionamiento ético del psicólogo en educación". Ponencia presentada en el I Congreso internacional de victimología, Ensenada, 24-26 de agosto, 2016. https://www.aacademica.org/ cristina.erausquin/23.pdf (acceso noviembre 15, 2019).

Farías, Leonel. "Violencia e inseguridad en las instituciones educativas: jóvenes en la mira de una sociedad del miedo". Cuadernos de Educación y Desarrollo (2013): 1-8. https://pdfs.semanticscholar.org/8306/4dac3845356684467df67e93dab57a5 
ffa00.pdf?_ga=2.47038439.1190364674.1586767786-232721732.1586767786 (acceso noviembre 15, 2019).

Fernández, Manuel. "La noción de violencia simbólica en la obra de Pierre Bourdieu: una aproximación crítica". Cuadernos de trabajo social 18, núm. 30 (junio 2005): 7-31. http://www.enlinea.cij.gob.mx/Cursos/Hospitalizacion/pdf/PierreBourdieu.pdf (acceso noviembre 15, 2019).

García, Clara, Álvaro Guzmán, Clara Aramburo, Alba Rodríguez y Juan Domínguez. "Ordenes locales y conflicto armado: una metodología comparada". Análisis Politico 27, núm. 81 (2014): 3-18. https://revistas.unal.edu.co/index.php/anpol/article/ view/45762 (acceso noviembre 15, 2019).

Gil Villa, Fernando. "La función social punitiva en Iberoamérica. Circunstancias globales y locales". URVIO. Revista Latinoamericana de Estudios de Seguridad, núm. 24 (2019): 10-25 (acceso noviembre 15, 2019).

Gómez, María. "La violencia de la publicidad contra la mujer". Questiones Publicitarias 1, núm. 20 (2015): 58-72. https://ddd.uab.cat/pub/quepub/quepub_a2015n20/ quepub_a2015n20p58.pdf (acceso noviembre 15, 2019).

González Ochoa, César. "Una teoría de la sociedad". Revista Cultura y Representaciones Sociales 12, núm. 24 (marzo 2018): 273-309. http://www.scielo.org.mx/pdf/crs/ v12n24/2007-8110-crs-12-24-273.pdf (acceso noviembre 15, 2019).

González, Anahí y Gabriela Plotnik. "Nosotros-otros', violencia simbólica y representaciones sociales sobre el migrante internacional. Un análisis en las instituciones educativa y judicial en la ciudad de Buenos Aires y Gran Buenos Aires". Argumentos, núm. 15 (noviembre 2013): 150-175. http://biblioteca.clacso.edu.ar/Argentina/iigguba/20140625053517/argumentos15-7.pdf (acceso noviembre 15, 2019).

Gutiérrez, Rafael y Leticia Vega. "La violencia simbólica de la explotación sexual de mujeres en una celebración estudiantil". Salud Mental 37, núm. 4 (julio-agosto 2014): 341-348. http://www.scielo.org.mx/scielo.php?script=sci_arttext\&pi $\mathrm{d}=$ S0185-33252014000400008 (acceso noviembre 15, 2019).

Krook, Lena y Juliana Restrepo. "Género y violencia política en América Latina. Conceptos, debates y soluciones”. Politica y Gobierno 13, núm. 1 (enero-junio 2016): 127-162. https://www.redalyc.org/pdf/603/60343614006.pdf (acceso noviembre 15, 2019).

Le Breton, David. Antropología del cuerpo y modernidad. Buenos Aires: Ediciones Nueva Visión, 2002.

Losada, Rodrigo y Andrés Casas. Enfoques para el análisis político: historia, epistemología y perspectivas de la ciencia politica. Bogotá: Pontificia Universidad Javeriana, 2008.

Maldonado Gómez, María. "Reseña de 'la dominación masculina' de Pierre Bourdieu". Sociedad yeconomía, núm. 4 (abril 2003): 69-74. https://www.redalyc.org/pdf/996/99617936012. pdf (acceso noviembre 15, 2019). 
Marín Mesa, Iván Andrés. "Análisis de la violencia simbólica en el conflicto armado en Colombia”. Tesis de pregrado, Pontificia Universidad Javeriana, 2013.

Martínez, Julia. "Violencia simbólica contra las mujeres". Pueblos (2011). http://www. revistapueblos.org/old/spip.php?article2290 (acceso noviembre 15, 2019).

Médor Bertho, Ducange. "Ser diferente en un mundo de semejanzas: ensayo sobre la dimensión simbólica de la vulnerabilidad". Iconos, núm. 64 (mayo 2019): 139-157. https://revistas.flacsoandes.edu.ec/iconos/article/view/3144 (acceso noviembre 15, 2019).

Mendes Catani, Afrânio, Alice Noguera, Ana Hey y Cristina Cardoso. Vocabulário Bourdieu. Belo Horizonte: Autêntica Editora, 2017.

Merino Obregón, Rubén. "La comprensión de la violencia de género como injusticia estructural". Cuestiones de género: de la igualdad y la diferencia, núm. 14 (2019): 9-27. http:// revpubli.unileon.es/ojs/index.php/cuestionesdegenero/article/view/5769/4475 (acceso noviembre 15, 2019).

Pérez Fonseca, Andrea. "La clasificación social del otro: formas de nombrar la 'peligrosidad' en el marco del conflicto armado colombiano". Análisis Político 28, núm. 84 (2015): 58-75. https://revistas.unal.edu.co/index.php/anpol/article/view/54639/54090 (acceso noviembre 15, 2019).

Pinzón Estrada, Carolina, Rosa Armas Guzmán, María Aponte Valverde y Martha Useche Morillo. "Percepción de la violencia simbólica en estudiantes universitarias. Análisis desde la categoría de género". Anfora 26, núm. 46 (enero-junio 2019): 89-110. https:// doi.org/10.30854/anf.v26.n46.2019.554 (acceso noviembre 15, 2019).

Posada Kubissa, Luisa. "Sobre Bourdieu, el habitus y la dominación masculina: tres apuntes". Revista de filosofía, núm. 73, (octubre 2017): 251-257. https://revistafilosofia.uchile. cl/index.php/RDF/article/view/47737/57429 (acceso noviembre 15, 2019).

Rincón, Stephania. "Cuerpos que se resisten a ser borrados: acompañamiento psicosocial a personas que habitan la calle". Tesis de pregrado, Corporación Universitaria Minuto de Dios, 2017.

Rivera, Geraldine y Angie Morera. "Comprensión de la naturalización y reproducción de la violencia contra la mujer. El caso de quince adultas mayores de la ciudad de Bogotá". Tesis de pregrado, Corporación Universitaria Minuto de Dios, 2017.

Rodríguez, Fabiana, Carolina González y Francisco Messenet. "Sátira política en las elecciones de 1935 y de 2016. Estudio comparativo de representaciones sociales femeninas en Topaze y The Clinic". Comunicación y Medios, núm. 39 (enero-junio 2019): 26-38. https://revistas.uchile.cl/index.php/RCM/article/view/51961 (acceso noviembre 15, 2019).

Sánchez-Perera, Paula. "Un debate adulterado: distribución del poder simbólico en las disputas feministas en torno a la prostitución". Revista Mediterránea de Comunicación 
10, núm. 1 (2019): 131-146. https://www.mediterranea-comunicacion.org/article/ view/2019-v10-n1-debate-adulterado-distribucion-poder-simbolico-disputasfeministas-prostitucion (acceso noviembre 15, 2019).

Serra, David. "Herencias coloniales y violencia simbólica en el conflicto armado peruano". Cuadernos de Filosofia Latinoamericana 35, núm. 113 (2015): 181-208. https://revistas. usantotomas.edu.co/index.php/cfla/article/view/2239/2585 (acceso noviembre $15,2019)$.

Serrano Barquín, Carolina, Héctor Serrano Barquín, Patricia Zarza-Delgado y Graciela Vélez-Bautista. "Estereotipos de género que fomentan violencia simbólica: desnudez y cabellera". Revista Estudos Feministas 26, núm. 3 (septiembre 2018): 1-14. https:// doi.org/10.1590/1806-9584-2018v26n344848 (acceso noviembre 15, 2019).

Sosa, Lorena y Mariana Grosso. "La prohibición de la violencia simbólica y mediática en la Argentina: ¿superación de la dicotomía público/privada?". Revista Electrónica. Instituto de Investigaciones Ambrosio L. Gioja, núm. 20, (junio-noviembre 2018): 156-185. http://www.derecho.uba.ar/revistas-digitales/index.php/revista-electronica-gioja/ article/view/368 (acceso noviembre 15, 2019)

Trujillo, Macarena. "Misoginia y violencia hacia las mujeres: dimensiones simbólicas del género y del patriarcado". Atenea (Concepción), núm. 519 (junio 2019): 49-64. https:// scielo.conicyt.cl/scielo.php?script=sci_arttext\&pid=S0718-04622019000100049 (acceso noviembre 15, 2019). 